\title{
Copper Futures' Risk Spillover Effects between SHFE and LME Based on EGARCH-GED
}

\author{
${ }^{1}$ Liu Jianhe \\ School of Finance \\ Zhejiang University of Finance and Economics, \\ Hangzhou, China \\ ${ }^{2}$ Wang Yubin* \\ College of Economics and Management \\ China Agricultural University, Beijing, China \\ Email: wyb@cau.edu.cn \\ * Corresponding Author
}

\author{
${ }^{1}$ Liang Renfang \\ School of Finance \\ Zhejiang University of Finance and Economics, \\ Hangzhou, China
}

\author{
${ }^{1} \mathrm{Hu}$ Qiong \\ School of Finance \\ Zhejiang University of Finance and Economics, \\ Hangzhou, China
}

\begin{abstract}
This paper calculates the VaR of copper futures' price in SHFE and LME during the Sub-prime mortgage crisis and the European debt crisis using the EGARCH-GED model. The direction and extent of spillover effects are checked with Granger causality test and impulse response function. The empirical results show that the two markets own mutual spillover effects during the U.S. Sub-prime mortgage crisis, while LME's spillover effects are stronger; and during the European debt crisis, LME has one-way spillover effects on SHFE. Therefore, we conclude that the SHFE's spillover effects on abroad markets depend on domestic economy, meanwhile it is necessary to take the abroad markets into consideration when supervising domestic financial market's risk.
\end{abstract}

Keywords-Risk Spillover; Value at Risk (VaR); EGARCHGED Model; Granger Causality Test.

\section{INTRODUCTION}

The linkage between financial markets in different countries or regions are increasingly stronger with the process of globalization, and the studies on linkage mechanism have been extended to information spillover effects from inter-markets' correlation. Depending on returns and risks, the inter-markets' spillover effects can be classified as mean spillover, volatility spillover and extreme downside spillover (Li Hong-quan, Hong Yongmiao and Wang Shou-yang, 2011[1]). However, scholars pay more attention on risk spillover effects between securities markets, the literature about spillover effects between different future markets is still undeveloped, not to mention risk spillover effects between similar commodities in different futures markets. Without pricing power on many commodity futures, future prices in mainland of China are easily influenced by other markets, such as LME, CME, etc. (Zhao Jin-wen, 2004[2]; Gao Hui and Zhao Jin-wen, 2007[3]; Pan Hui-feng and Zhang Jinshui, 2007[4]; Lu Feng-bin and Hong Yong-miao, 2012[5]; etc.). As Chinese copper future market is developing rapidly, these connections with other international markets is increasingly close. Wang Jia-hui (2008) [6] argued that the SHFE' $s$ international pricing power of copper futures has overtaken New York mercantile exchange and came to the second place in the world market. Song Jun and $\mathrm{Li}$ Peng(2007)[7] pointed out that the London metal exchange (LME) was today's copper future global pricing center of the supply side, while the Shanghai futures exchange (SHFE) has become the pricing center of the demand side. But due to the limits of China' $s$ futures market development, academic researchers usually focused on relations between the market price revelation and market lags effects. Research on risk spillover is essential to avoid financial risk spillover from one market to another. Therefore, we believe the studies on spillover effects of inter-regional futures markets are not only beneficial for forecasting risk spillover from other futures markets, but also meaningful for both financial market participants and supervisors.

\section{LITERATURE REVIEW}

Wherever Times is specified, Times Roman or Times New Roman may be used. If neither is available on your word processor, please use the font closest in appearance to Times. Avoid using bit-mapped fonts if possible. TrueType 1 or Open Type fonts are preferred. Please embed symbol fonts, as well, for math, etc. Scholars started to study on inter-markets spillover effects from 1980' s. Garbade and Silber (1983) [8] found the phenomenon that future prices change before spot prices do and used GS model to test the role of futures and spot goods in price discovery. At all, the spillover effect models can be divided into three kinds: one-moment models (such as the liner model, cointegration model, VAR and ECM, etc.) two-moment models (such as volatility variance model and ARCH group) and higher moment models.

Most studies have employed two-moment models and higher moment models. For example, Hamao, Masulis and Ng (1990) [9], Sadorsky (2002) [10] respectively used ARCH to study information spillover effects between stock market and oil future market. Korkie et al.(2006) [11] and Hashmi and Tay (2007) [12] studied three-moment 
model as well as its applications, and figured out that timevarying skewness can improve measurement accuracy of risk spillover effect. However, studies on risk spillover effects of Chinese financial markets still focus on one and two moment model. Hong and his partners apply one and two-moment models with variance time-varying effects to study financial risk volatile spillover (Hong, 1996[13]; Hong, 2001[14]; Hong et al., 2004[15]; Hong et al., 2009[16]; Li Hong-quan, Hong Yong-miao and Wang Shou-yang, 2011; Lu Feng-bin and Hong Yong-miao, 2012).

In conclusion, the existing literature on risk spillover effects of Chinese financial markets pays more attention to the application of lower moment models. Besides, most recent studies focus on security markets instead of futures market. Some literature tests causal relationship between future price and spot goods price, but ignore the effects of futures markets in other regions on those in China. The latest empirical studies on risk spillover effects of Chinese financial markets only involve data of 2010, it is necessary to update the data to check spillover effects during the periods of U.S. subprime mortgage crisis and European debt crisis.

Most studies on risk spillover effects use GARCH model. For example, Zhao Liu-yan and Wang Yi-ning (2003)[17], Dong Xiu-liang and Cao Feng-qi(2009)[18]use GARCH to study spillover effects among different stock markets .What' s more ,Chen Yun et.al. (2008)[19] study the spillover effects between RMB exchange rate and stock market by means of BV-GARCH-BEKK model. At the same time, GARCH model has been widely performed in futures market. Shen Pei-long and Xing Tong-zheng (2010) [20], Cai Jian et.al (2011) [21] use GED -GARCH model to study the spillover effects between WTI market and the oil market. Liu et al. (2015) [22] use EGARCH model to study the spillover effects about soybean futures between DCE soybean and CBOT soybean, because spillover effects may be asymmetric, this paper tests different types of information influence on markets with EGARCH model rather than GARCH model. Meanwhile, because distribution characteristics of financial time series may be negatively skewed and leptokurtosis, this paper replaces normal distribution or $t$ distribution with generalized error distribution (GED). Actually, Chen Y.R. (2010) [23] and Tao Wei (2012) [24] find that GED is more fitful to estimate VaR than normal distribution and $t$ distribution, the tail of normal distribution is too thin to underestimate risk and that of $\mathrm{t}$ distribution is too thick to overestimate risk.

To deal with the shortcomings of existing studies, this paper starts with an introduction of research methodology after literature review. Then we put forward our models and apply EGARCH-GED to estimate VaR of copper future time series of SHFE and LME. Based on long market and short market of copper future, the paper uses Granger causality to test risk spillover effects and analyzes spillover direction and process with impulse response test. At last, we summarize the empirical results and make some policy recommendations.

\section{RESEARCH METHODS}

\section{A. VaR}

The risk measurement methods usually are variance, semi-variance, and lower partial moment, etc., and the most representative approach is Value at risk (VaR). VaR can be defined as the maximum loss on some asset or portfolio over a given period of time with a given confidence level. As shown in equation (1).

$$
\operatorname{Pr}\left(\mathrm{R}_{\mathrm{t}}>-\mathrm{VaR}_{\mathrm{t}}\right)=1-\alpha \text { or } \operatorname{Pr}\left(\mathrm{R}_{\mathrm{t}}<-\mathrm{VaR}_{\mathrm{t}}\right)=\alpha(1)
$$

where Rt denotes the return (or loss) of asset or portfolio during time t. Given the confidence level of $(1-\alpha)$ and probability density function $\mathrm{f}(\mathrm{p})$, we define Rt's minimum level as $\mathrm{p}^{*}$, therefore the probability that $\mathrm{Rt}>\mathrm{p}^{*}$ is $(1-\alpha)$. As shown in equation (2).

$$
1-a=\int_{P^{*}}^{\infty} f(p) d p
$$

where $p^{*}$ is the $\mathrm{VaR}$ which presents the quantile in statistics

\section{B. EGARCH-GED Model}

Engle (1982) [25] introduced conditional variance to explain the reason of variance change, and developed autoregressive conditional heteroscedasticity model (ARCH). Based on previous scholars' achievements, Nelson (1991) [26] developed EGARCH model to improve GARCH ' $s$ inefficiency in measuring asymmetric volatility, as shown in equation (3).

$$
\ln \sigma_{t}^{2}=\omega+\sum_{i=1}^{q} \theta_{i}\left|\frac{\varepsilon_{t-i}}{\sigma_{t-i}}-E\left(\frac{\varepsilon_{t-i}}{\sigma_{t-i}}\right)\right|+\sum_{k=1}^{r} \gamma_{k} \frac{\varepsilon_{t-k}}{\sigma_{t-k}}+\sum_{j=1}^{p} \beta_{j} \ln \sigma_{t-j}^{2}
$$

when $\gamma_{k} \neq 0$, the effects of different news (good or bad) are asymmetric. In this paper, we find that EGARCH $(1,1)$ gets the best estimated results. So equation (3) can be simplified to equation (4).

$$
\ln \sigma_{t}^{2}=\omega+\theta\left|\frac{\varepsilon_{t-1}}{\sigma_{t-1}}\right|+\gamma \frac{\varepsilon_{t-1}}{\sigma_{t-1}}+\beta \ln \sigma_{t-1}^{2}
$$

Here we denote that the residual series $\eta_{t}=\frac{\varepsilon_{t}}{\sigma_{t}}$ is subject to generalized error distribution (GED), as shown in equation (5).

$$
f\left(\eta_{t}\right)=\frac{c \exp \left[-\frac{1}{2}\left|\eta_{t} / \lambda\right|^{c}\right]}{\lambda 2^{[(c+1) / c]} \Gamma\left(\frac{1}{c}\right)}
$$

where $\Gamma(\bullet)$ is a gamma function and $c$ is a positive parameter which implies the residual distribution is tail shape. Specifically, when $\mathrm{c}=2, \eta_{t} \sim N(0,1)$; when $\mathrm{c}<2$, it has fatter tail than normal distribution and the kurtosis is larger than three; and c>2 indicates the thinner tail. And 


$$
\lambda=\left[\frac{2^{(-2 / c)} \Gamma\left(\frac{1}{c}\right)}{\Gamma\left(\frac{3}{c}\right)}\right]
$$

\section{Granger Causality Test}

Granger (1969) [27] redefined causality from the perspective of one-time series predicting power over another one's changes, therefore Granger causality denotes "reason" as the information (or phenomena) occurs firstly and "result" as the information (or phenomena) occurs subsequently. Granger (1969) and Sims (1972) [28] both mentioned that when variable $\mathrm{x}$ is useful for predicting variable $\mathrm{y}$, that is, if past values of $\mathrm{X}$ can be significantly enhanced the explanatory power of $y$ 's autoregression model, $x$ is the Granger cause of $y$ $(x \Rightarrow y$ ), otherwise $\mathrm{x}$ is not the Granger cause of $\mathrm{y}$. Granger causality test could be modelled as equation (7).

$$
y_{t}=\sum_{i=1}^{k} \alpha_{i} y_{t-i}+\sum_{i=1}^{k} \beta_{i} x_{t-i}+u_{1 t}
$$

where $\alpha$ and $\beta$ are parameters, $\mathrm{k}$ is the maximum number of lags. Here the null hypothesis is H0: $\beta_{1}==\beta_{2} \cdots$ $=\beta_{k}=0$, which means $x$ is not y's Granger cause. Then we setup the regression model including $\mathrm{x}$ (constrained) and excluding $\mathrm{x}$ (unconstrained) respectively, denote residual sum of squares of the constrained model including $\mathrm{x}$ as $\mathrm{SSEu}$ and that of the unconstrained model excluding $\mathrm{x}$ as SSEr. This paper uses equation (8) to calculate F statistic.

$$
F=\frac{\left(S S E_{r}-S S E_{u}\right) / k}{S S E_{u} /(N-n)}
$$

where $\mathrm{N}$ is the sample size and $\mathrm{n}$ is number of parameters to be estimated in the unlimited regression model. When $\mathrm{H} 0$ is true, $F \sim F_{\alpha}(k, N-n)$. And if the $\mathrm{F}$ statistics calculated with equation (8) is larger than $F_{\alpha}(k, N-n)$, we should reject the null hypothesis, which confirm y's Granger causality is $\mathrm{x}$.

\section{Impulse Response Function}

When we estimate vector autoregression (VAR) model's parameters with ordinary least square (OLS), it's difficult to explain the economic meaning of single parameter estimate. It is necessary to analyze VAR model, and this paper uses the method of impulse response function (IRF) to study the process of risk spillover effects between SHFE and LME.

IRF describes reaction of endogenous variables to error shock. The shock might be policy changes or the changes of market information, etc. IRF presents the reaction of endogenous variable's current and future value when the random error term is given a standard shock. Assuming that the $\mathrm{N}$-dimension stochastic disturbance column vector of VAR model in lagging $p$ periods is white noise sequence, and that the covariance of VAR is stable, VAR (p) can be expressed by equation (9)

$$
\mathbf{y}_{\mathrm{t}}=\boldsymbol{\mu}+\mathbf{u}_{\mathrm{t}}+\boldsymbol{\Psi}_{1} \mathbf{u}_{\mathrm{t}-\mathbf{1}}+\boldsymbol{\Psi}_{2} \mathbf{u}_{\mathrm{t}-\mathbf{2}}+\cdots=\boldsymbol{\mu}+\boldsymbol{\Psi}(L) \mathbf{u}_{\mathrm{t}}
$$

where the $\mathrm{i}$-th row and $\mathrm{j}$-th column element in

coefficient matrix $\boldsymbol{\Psi}_{s}$ represents the variable i's reaction after $s$ periods to variable $j$ 's unit shock, i.e. variable i's impulse response of $s$ periods to variable $j$. The matrix definition of IRF is as equation (10).

$$
\frac{\partial \mathrm{y}_{\mathrm{t}+\mathrm{s}}}{\partial \mathrm{u}_{\mathrm{t}}^{\prime}}=\boldsymbol{\Psi}_{s}
$$

\section{RESULTS AND DISCUSSION}

\section{A. Data}

In this paper we choose daily closing price of copper futures in SHFE and LME from 1st July, 2007 to 1st July, 2012. This sample period covers U.S. subprime mortgage crisis and European debt crisis.

Because of the different holidays in China and Britain, we eliminate SHFE data during British holidays and LME data during Chinese holidays. Meanwhile, LME copper futures are quoted in USD whereas SHFE in RMB, we change the close prices of copper future in LME in RMB according to middle exchange rate of RMB/USD published by State Administration of Foreign Exchange (http://www.safe.gov.cn/). For the purpose of comparing the spill over effects during the period of U.S. subprime mortgage crisis with those during the period of European debt crisis, this paper divides the total sample into two sub-samples: sub-sample 1 is from 1st July, 2007 to $31 \mathrm{st}$ Dec., 2009. This sub-sample period is the period of U.S. sub-prime mortgage crisis; sub-sample 2 is from 1st Jan., 2010 to 1 st July, 2012. This sub-sample period is the period of European debt crisis.

To stabilize the data series and avoid heteroscedasticity, we use the logarithmic return in this paper. Logarithmic return is calculated according to equation (11)

$$
R_{t}=\ln p_{t}-\ln p_{t-1}
$$

where $\mathrm{p}_{\mathrm{t}}$ is return at $\mathrm{t}$ period; $\mathrm{pt}$ and $\mathrm{p}_{\mathrm{t}-1}$ are prices at $\mathrm{t}$ period and $t-1$ period respectively.

The return series of SHFE and LME are apparently different, but both share volatility clustering. That is, abnormal volatility always follows abnormal volatility and slight volatility always follows slight volatility. Denoting the return series of SHFE is Rt(SHFE) and that of LME is $\mathrm{Rt}(\mathrm{LME})$. The results show that both $\mathrm{Rt}(\mathrm{SHFE})$ and $\operatorname{Rt}(\mathrm{LME})$ share negative skewness, leptokurtosis and positive JB-test, which verifies the distribution of return series is leptokurtic with fat tail. Both return series' ADF tests are significant at $1 \%$ confidence level. Both return series are stationary.

\section{B. VaR Estimation}

The descriptive statistics results show that returns of both markets are left skewed and leptokurtic without autocorrelation. We set up mean equation on logarithmic price series $\ln p_{t}$ as equation (12)

$$
. \ln p_{t}=\lambda \ln p_{t-1}+\varepsilon_{t}
$$

Then we estimate the logarithmic price series with EGARCH $(1,1)-G E D$ and the results are shown in Table I 
TABLE I Estimation results of EGARCH $(1,1)-G E D$

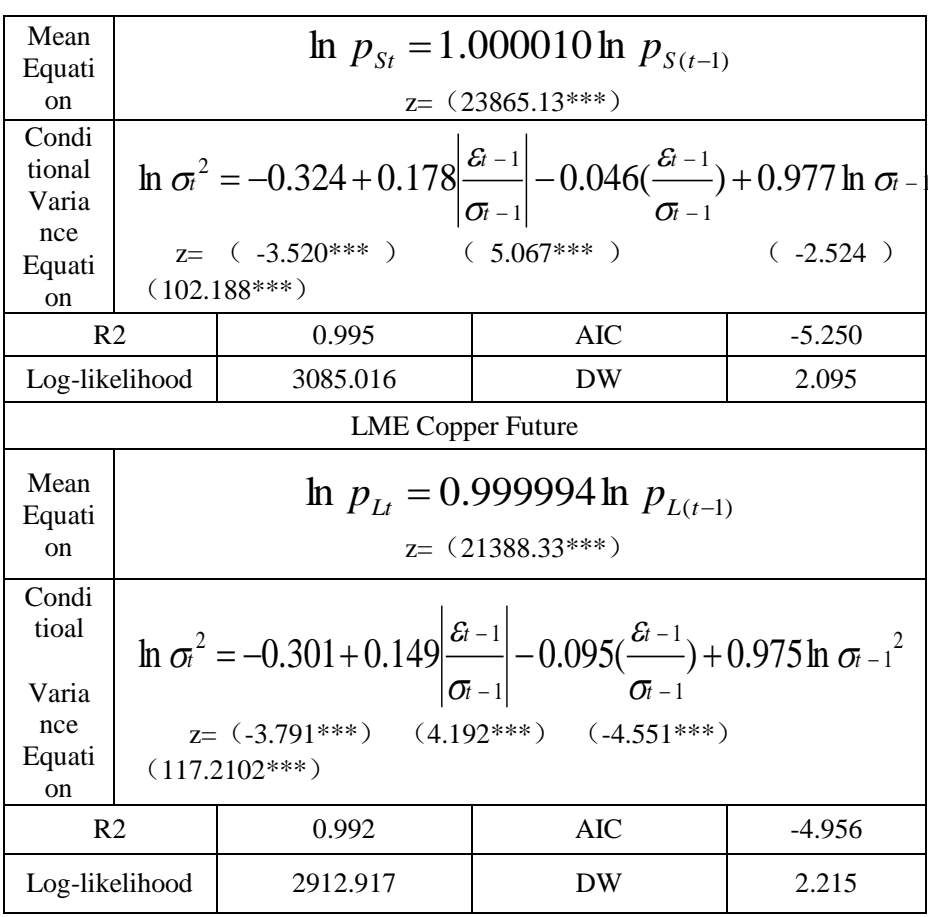

Note: $* * *$ refers to be significant at 0.01 confidence level.

There are some interesting findings from Table1. Firstly, the GARCH item's parameters of both markets are quite close to 1 , which means there is persistent shock on conditional variance. Secondly, the asymmetric item's parameter of both markets is -0.046 and -0.095 respectively. The negative parameters mean the shock of bad news is much huger than that of good news. But the asymmetric item's parameter of SHFE is not significant in total sample period. Thirdly, $\theta$ and $\beta$ of SHFE copper future are larger than those of LME copper future, which means that SHFE market is more easily influenced by short term factors and LME by long term factors. Fourthly, the ARCH-LM test results show that p-values of Fstatistics and TR2 are significantly more than 0.01 , which confirms EGARCH model eliminates the influence of conditional heteroscedasticity.

Before calculating the VaR of both markets, we still need GED degree and quantile as following Table II. Here we choose significant level at $5 \%$ and $10 \%$.

TABLE II GED Quantile

\begin{tabular}{|c|c|c|c|c|}
\hline Parameter c & \multicolumn{2}{|c|}{$\mathrm{cS}=1.457765<2$} & \multicolumn{2}{c|}{$\mathrm{cL}=1.404127<2$} \\
\hline Sig. & $5 \%$ & $10 \%$ & $5 \%$ & $10 \%$ \\
\hline Right side quantile & 1.653 & 1.233 & 1.652 & 1.225 \\
\hline Left side quantile & -1.653 & -1.233 & -1.652 & -1.225 \\
\hline
\end{tabular}

With the estimated volatility in Table 1 and quantiles in Table 2, we can calculate the VaR by equation (13).

$$
\operatorname{VaR}_{t}=p_{t-1}\left(1-e^{\kappa \sigma_{t}}\right)
$$

where Pt-1 is the close price at $\mathrm{t}-1$ period; $\kappa$ is the quantile at corresponding level. When the futures are in long position, $\kappa$ is the left side quantile; and when the futures are in short position, $\kappa$ is the right side quantile.
Risks of long positon come from increased price and payment, while risks of short position are from decreased price and income. Because $\mathrm{VaR}$ is negative when futures are in short position, we take absolute values of $\mathrm{VaR}$ to maintain comparability.

Table III is the descriptive statistics of VaR in both markets. Both in long market and short market, daily average loss of LME copper future is greater than that of SHFE copper future, but the difference is not large. Maximum and minimum potential losses of LME copper future means that LME copper future has stronger volatility. Standard deviation of $\mathrm{VaR}$ in short market is bigger than that in long market for both markets. It shows that risk is greater in short market than that in long market.

TABLE III Descriptive statistics of VaR for SHFE and LME copper futures

\begin{tabular}{|c|c|c|c|c|}
\hline \multicolumn{5}{|c|}{ SHFE Copper Future } \\
\hline \multirow[b]{3}{*}{ Mean } & \multicolumn{2}{|c|}{ Long Market } & \multicolumn{2}{|c|}{ Short Market } \\
\hline & $\operatorname{VaR}(0.05)$ & $\operatorname{VaR}(0.10)$ & $\operatorname{VaR}(0.05)$ & $\operatorname{VaR}(0.10)$ \\
\hline & 1612.406 & 1207.572 & 1664.674 & 1236.652 \\
\hline Medium & 1552.187 & 1161.585 & 1598.684 & 1188.091 \\
\hline Max. & 2808.656 & 2108.967 & 2960.413 & 2193.395 \\
\hline Min. & 915.1241 & 686.126 & 937.189 & 697.742 \\
\hline Std.Dev. & 372.172 & 279.624 & 394.351 & 291.962 \\
\hline Skewness & 0.497 & 0.504 & 0.548 & 0.542 \\
\hline Kurtosis & 2.594 & 2.607 & 2.712 & 2.695 \\
\hline JB-test & 56.444 & 57.134 & 62.827 & 61.881 \\
\hline \multicolumn{5}{|c|}{ LME Copper Future } \\
\hline & \multicolumn{2}{|c|}{ Long Market } & \multicolumn{2}{|c|}{ Short Market } \\
\hline & $\operatorname{VaR}(0.05)$ & $\operatorname{VaR}(0.10)$ & $\operatorname{VaR}(0.05)$ & $\operatorname{VaR}(0.10)$ \\
\hline Mean & 1624.741 & 1210.76 & 1688.806 & 1245.984 \\
\hline Medium & 1533.279 & 1141.486 & 1582.848 & 1169.398 \\
\hline Max. & 4006.573 & 3016.786 & 4519.473 & 3298.638 \\
\hline Min. & 758.266 & 563.2 & 786.004 & 568.554 \\
\hline Std.Dev. & 420.382 & 315.624 & 464.173 & 339.689 \\
\hline Skewness & 1.629 & 1.666 & 1.933 & 1.892 \\
\hline Kurtosis & 7.918 & 8.136 & 9.759 & 9.5 \\
\hline JB-test & 1700.873 & 1831.968 & 2963.438 & 2765.163 \\
\hline
\end{tabular}

Note: VaR (0.05) means VaR at 5\% significant level, $\mathrm{VaR}(0.10)$ means $\mathrm{VaR}$ at $10 \%$ significant level. 
Now we can figure out the $\mathrm{VaR}$ of both markets and carry out validity test. Supposing $\Delta \mathrm{Pt}=\mathrm{Pt}-\mathrm{Pt}-1$, when the probability of $\Delta \mathrm{Pt}>\mathrm{VaRt}$ is higher than corresponding significant level, the estimated VaRt is invalid, or it is valid. The results of validity test are shown in Table 4. Most probability values are less than corresponding significant level, the estimated VaRt is valid. We also can use likelihood ratio (LR-statistics) to test validity of estimated VaRt. Likelihood ratio is defined as equation (14).

$$
L R=-2\left\{\ln \left[(1-\alpha)^{T-N} \alpha^{N}\right]-2 \ln \left[(1-f)^{T-N} f^{N}\right]\right\}
$$

Where $\mathrm{T}$ is the sample size; $\mathrm{N}$ is actual number of failures; $f=N / T$ is failure frequency. LR-statistics follow chi square distribution with freedom degree of 1 , and the critical values are 3.84 and 2.71 at $5 \%$ and $10 \%$ significant level respectively. LR-statistics of VaR in both markets are listed in Table IV. The results of LR are less than critical values. It also shows that the estimated VaRt is valid. Therefore, we can accept EGARCH-GED model and estimated VaRt.

Table IV Validity test of VaR

\begin{tabular}{|c|c|c|c|c|}
\hline \multicolumn{5}{|c|}{ SHFE Copper Future } \\
\hline $\begin{array}{c}\text { Significant } \\
\text { level }\end{array}$ & $5 \%$ & $10 \%$ & $5 \%$ & $10 \%$ \\
\hline $\mathrm{N}\left(\Delta P_{t}>\right.$ VaR $\left._{t}\right)$ & 53 & 109 & 49 & 106 \\
\hline Probability & $4.52 \%$ & $9.29 \%$ & $4.18 \%$ & $9.04 \%$ \\
\hline LR & 0.591 & 0.667 & 1.766 & 1.246 \\
\hline \multicolumn{5}{|c|}{ LME Copper Future } \\
\hline $\begin{array}{c}\text { Significant } \\
\text { level }\end{array}$ & $5 \%$ & $10 \%$ & $5 \%$ & $10 \%$ \\
\hline $\mathrm{N}\left(\Delta P_{t}>V_{\text {VaR }}\right)$ & 55 & 119 & 50 & 116 \\
\hline Probability & $4.69 \%$ & $10.14 \%$ & $4.26 \%$ & $9.80 \%$ \\
\hline LR & 0.244 & 0.027 & 1.410 & 0.006 \\
\hline
\end{tabular}

\section{Spillover Effect Test}

After estimating VaR values with EGARCH-GED for both markets, we can test spillover effects. Before spillover effect test, we need stationary test of $\mathrm{VaR}$ values. According to critical value at $5 \%$, the results of stationary test show that the VaR values of SHFE and LME copper future markets are stationary, which are able to applied to Granger causality test with vector auto-regression (VAR) model. And Table $\mathrm{V}$ lists the optimal lagging periods decided by AIC principle. TableVIis the corresponding results of Granger causality.

Table V Optimal lagging periods for Granger causality test

\begin{tabular}{|c|c|c|c|c|c|c|}
\hline & \multicolumn{3}{|c|}{ Long Market } & \multicolumn{3}{c|}{ Short Market } \\
\hline & $\begin{array}{c}\text { Sub- } \\
\text { sample } \\
1\end{array}$ & $\begin{array}{c}\text { Sub- } \\
\text { sample } \\
2\end{array}$ & $\begin{array}{c}\text { Total } \\
\text { Sampl } \\
\mathrm{e}\end{array}$ & $\begin{array}{c}\text { Sub- } \\
\text { sample } \\
1\end{array}$ & $\begin{array}{c}\text { Sub- } \\
\text { sample } \\
2\end{array}$ & $\begin{array}{c}\text { Total } \\
\text { Sampl } \\
\mathrm{e}\end{array}$ \\
\hline $\begin{array}{c}\text { VaR } \\
(0.05)\end{array}$ & 5 & 2 & 5 & 5 & 4 & 5 \\
\hline $\begin{array}{c}\text { VaR } \\
(0.10)\end{array}$ & 5 & 2 & 5 & 5 & 4 & 5 \\
\hline
\end{tabular}

In sub-sample1, there are mutual spillover effects between SHFE and LME, while only one-way spillover effect of LME on SHFE in sub-sample2 and total sample. Furthermore, this evidenced that China's copper future market is increasingly important among international copper future markets and gets more and more pricing power of copper. At the same time, it is still impacted by other markets. We believe that in the period of U.S. Subprime mortgage crisis, the copper demand of other regions and countries declined sharply, and the mainland of China was impacted little and kept higher copper demand. This caused the mutual spillover effects between SHFE and LME copper futures. In the period of European debt crisis, copper demand of mainland of China declined too, which decreased SHFE's impacts on LME copper future. There was one-way spillover effect again.

Table VI Granger causality test of SHFE and LME copper future risk spillover base on $\mathrm{VaR}$

\begin{tabular}{|c|c|c|c|c|c|c|}
\hline & & & \multicolumn{2}{|c|}{ Long Market } & \multicolumn{2}{|c|}{ Short Market } \\
\hline & & & $\begin{array}{c}\text { LME } \\
\text { Copper } \\
\text { Future } \\
\text { Risk is } \\
\text { not } \\
\text { SHFE } \\
\text { one's } \\
\text { Cause }\end{array}$ & $\begin{array}{c}\text { SHFE } \\
\text { Copper } \\
\text { Future } \\
\text { Risk is } \\
\text { not LME } \\
\text { one's } \\
\text { Cause }\end{array}$ & $\begin{array}{c}\text { LME } \\
\text { Copper } \\
\text { Future } \\
\text { Risk is } \\
\text { not } \\
\text { SHFE } \\
\text { one's } \\
\text { Cause }\end{array}$ & $\begin{array}{c}\text { SHFE } \\
\text { Copper } \\
\text { Future } \\
\text { Risk is } \\
\text { not LME } \\
\text { one's } \\
\text { Cause }\end{array}$ \\
\hline \multirow{4}{*}{ 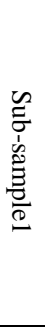 } & \multirow{2}{*}{$\begin{array}{c}\mathrm{VaR}(0 \\
.05)\end{array}$} & $\begin{array}{c}\text { F- } \\
\text { statisti } \\
\text { cs }\end{array}$ & 14.445 & 2.493 & 14.458 & 2.380 \\
\hline & & $\begin{array}{c}\mathrm{p}- \\
\text { value }\end{array}$ & $2.4 \mathrm{E}-13$ & 0.030 & $2.3 \mathrm{E}-13$ & 0.037 \\
\hline & \multirow{2}{*}{$\begin{array}{c}\mathrm{VaR}(0 \\
.10)\end{array}$} & $\begin{array}{c}\text { F- } \\
\text { statisti } \\
\text { cs } \\
\end{array}$ & 14.443 & 2.477 & 14.455 & 2.393 \\
\hline & & $\begin{array}{c}\mathrm{p}- \\
\text { value }\end{array}$ & $2.4 \mathrm{E}-13$ & 0.030 & $2.3 \mathrm{E}-13$ & 0.037 \\
\hline \multirow{4}{*}{ 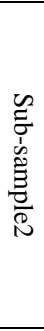 } & \multirow{2}{*}{$\begin{array}{c}\mathrm{VaR}(0 \\
.05)\end{array}$} & $\begin{array}{c}\text { F- } \\
\text { statisti } \\
\text { cs } \\
\end{array}$ & 42.249 & 0.546 & 24.468 & 1.252 \\
\hline & & $\begin{array}{c}\mathrm{p}- \\
\text { value }\end{array}$ & $7.8 \mathrm{E}-18$ & 0.580 & $1.1 \mathrm{E}-18$ & 0.288 \\
\hline & \multirow{2}{*}{$\begin{array}{c}\mathrm{VaR}(0 \\
.10)\end{array}$} & $\begin{array}{c}\text { F- } \\
\text { statisti } \\
\text { cs } \\
\end{array}$ & 42.422 & 0.540 & 24.358 & 1.244 \\
\hline & & $\begin{array}{c}\mathrm{p}- \\
\text { value }\end{array}$ & $6.7 \mathrm{E}-18$ & 0.583 & $1.3 \mathrm{E}-18$ & 0.291 \\
\hline \multirow{4}{*}{$\begin{array}{l}\overrightarrow{0} \\
\stackrel{0}{0} \\
\tilde{\infty} \\
\hat{\tilde{E}} \\
\frac{\tilde{\sigma}}{0}\end{array}$} & \multirow{2}{*}{$\begin{array}{c}\mathrm{VaR}(0 \\
.05)\end{array}$} & $\begin{array}{c}\text { F- } \\
\text { statisti } \\
\text { cs } \\
\end{array}$ & 30.818 & 1.601 & 31.040 & 1.485 \\
\hline & & $\begin{array}{c}\mathrm{p}- \\
\text { value }\end{array}$ & $1.7 \mathrm{E}-29$ & 0.157 & $1.0 \mathrm{E}-29$ & 0.192 \\
\hline & \multirow[t]{2}{*}{$\begin{array}{c}\mathrm{VaR}(0 \\
.10)\end{array}$} & $\begin{array}{c}\text { F- } \\
\text { statisti } \\
\text { cs } \\
\end{array}$ & 30.850 & 1.584 & 31.019 & 1.498 \\
\hline & & $\begin{array}{c}\text { p- } \\
\text { value }\end{array}$ & $1.6 \mathrm{E}-29$ & 0.161 & $1.1 \mathrm{E}-29$ & 0.188 \\
\hline
\end{tabular}

\section{On Spillover Effect}

To study the process and direction of spillover effects in long and short markets of SHFE and LME, we apply impulse response function in this paper. On the one hand, the degree of risk spillover increases with the increasing significant level. On the other hand, the processes of risk spillover at different significant level are similar. So we choose the IRF of long market at 5\% significant level. 

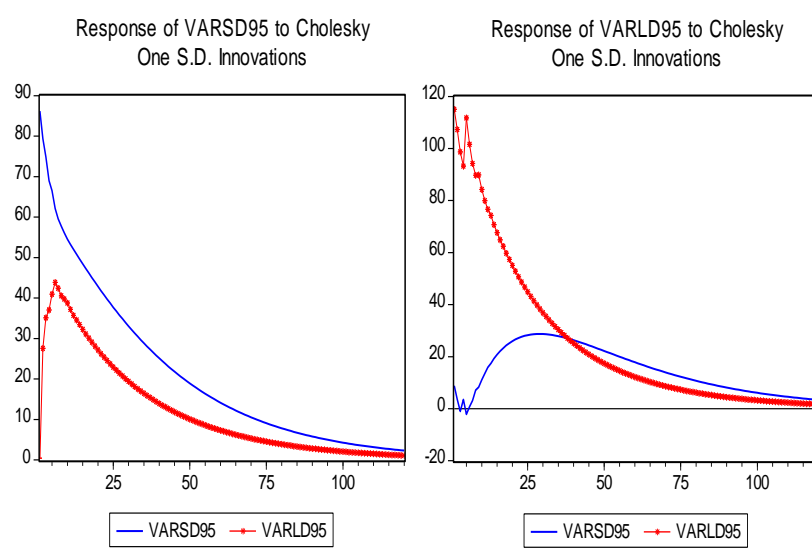

Figure 1. Impulse Response of Spillover between SHFE and LME Long Market in Sub-Sample1

Figure .1 Impulse response of spillover between SHFE and LME long market in sub-sample1Notes: VARSD95 represents the VaR of SHFE long market at 5\% significant level; VARLD95 represents the VaR of LME long market at 5\% significant level. The left figure in Figure 1 shows SHFE's response when facing one standard innovation shock, while the right one is LME's. The mutual spillover effects last quite long because impacts do not vanish for more than 100 periods, and we should also notice that LME's impact is much stronger than SHFE's because the left figure's red line (LME's impact on SHFE when a standard innovation occurs) has a higher peak than right one's blue line (SHFE's impact on LME when a standard innovation occurs). Moreover, the speed of LME's positive impact on SHFE is faster and increases quickly in first 10 periods, while LME's response on SHFE's impact is lagged to $25 \sim 30$ periods. It is interesting that two lines do not cross in left figure and cross at the 37 th period in right figure. It means that standard innovation shocks of SHFE's own risk spillover are much stronger than that come from LME's, standard innovation shocks of LME's own risk spillover are weaker than that come from SHFE's after 37 periods.
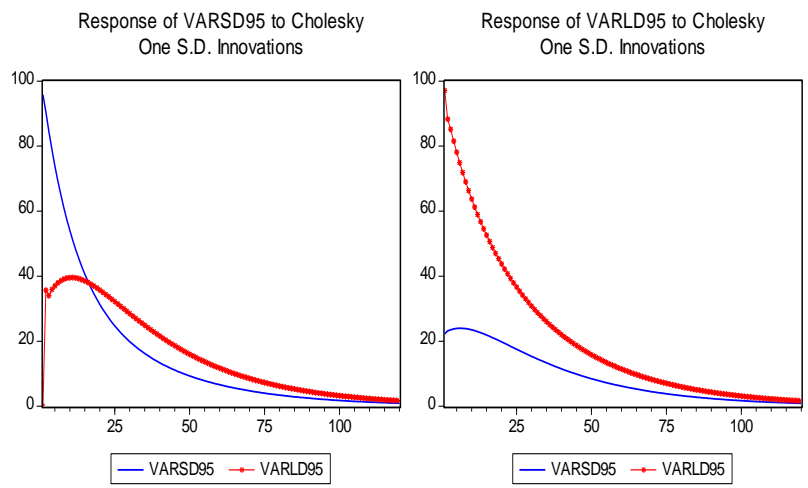

Figure 2. Impulse Response of Spillover between SHFE and LME Long Market in Sub-sample2

Figure .2 illustrates both markets' responses when facing a standard innovation in sub-sample2. The similarity with Figure 1 is that both markets' responses of own risk spillover are forward decreasing and tend to 0 at last. But when facing LME's shock, SHFE's positive spillover increases quickly in first 3 periods, reach the peak at 10 15 periods and then forward decreases (left figure in Figure 2); whereas LME's spillover is stably and gradually vanishing when facing SHFE's shock (right figure in Figure 2). Furthermore, LME's impact on SHFE is stronger than SHFE's impact on LME. LME's risk spillover shock is stronger than that of SHFE's.

Our test results show that the spillover effects of copper futures markets are different in two sub-sample periods. In the period of sub-sample1, the period of U.S. sub-prime mortgage crisis, mainland of China has taken active fiscal and loose monetary policy and achieved a better macro-economy than other more developed countries. Imported copper data from 2006 to 2009 in China shows that copper demand was strong. Against other countries' weak copper demand, strong demand in mainland of China naturally made price impact of SHFE copper future on LME one. In the period of sub-sample2, the period of European debt crisis, copper demand in mainland of China declined and the number of imported copper decreased (the number of imported copper in 2010 was less than that in 2009). That's why in the period of sub-sample2, SHFE suffered a stronger shock from LME rather than its own after 15 periods (the left figure in Figure 2).

\section{CONCLUSION}

Copper, as a kind of metal, occupies extremely important role in modern society's production and life, so research on its market risk is meaningful both in practice and theory. In this paper, we set up EGARCH-GED model to estimate volatility and VaR of SHFE and LME copper futures, test the risk spillover effects and the direction and process of risk spillover between SHFE and LME. It is not difficult to get the following conclusions:

1) There are mutual risk spillover effects between SHFE copper future and LME one during the period of U.S. sub-prime crisis. The reason is that better macroeconomy and growing demand for copper in mainland of China influenced copper price in international markets, which induced SHFE's spillover effect on LME. In the period of U.S. sub-prime crisis, LME owned a process of repeated revising when facing a standard innovation shock but SHFE did not. It is also an evidence of better performed economy in mainland of China in the period of sub-sample1.

2) There was only one-way risk spillover effect of LME copper future on SHFE one during the period of European debt crisis. In the period of sub-sample2, LME is SHFE's Granger cause but not vice versa. The reason was the decline copper demand in mainland of China.

Generally speaking, we may draw lessons from the empirical conclusions. Macro-economy is the foundation of pricing power of domestic financial markets. With the globalization of domestic copper futures market, its international influence power depends on macroeconomy's improvement. And when the risks of foreign markets have stronger spillover effects on domestic market, it is necessary to supervise risks spillover effects of foreign markets. Regulatory authorities should focus on risk spillover process, direction and efficiency of 
international markets, which is fairly important to monitor, control and prevent risk and establish a risk warning system.

\section{ACKNOWLEDGMENT}

This paper is sponsored by Zhejiang Provincial Natural Science Foundation (No. Y16G030044 and LY14G030013).

\section{REFERENCES}

[1] Li Hong-quan, Hong Yong-miao, Wang Shou-yang. Information Spillover among China' s A-shares Market, US Stock Market and HK Stock Market[J]. Economic Research Journal, 2011, 08:1525.

[2] Zhao Jin-wen. Analysis of the Association between Chinese and International Commodity Futures Markets and Associated CoIntegration Tests[J]. China Soft Science Magazine, 2004, 05:34-40.

[3] Gao Hui, Zhao Jin-wen. The Empirical Research of Futures Price Return and Volatilities in Shanghai of China and London of UK[J]. Research on Financial and Economic Issues, 2007, 02:54-66.

[4] Pan Hui-feng, Zhang Jin-shui. The Extreme Risk Spillover Effect between International and Domestic Oil Markets[J]. Chinese Journal of Management Science, 2007, 15(3): 25-30.

[5] Lu Feng-bin, Hong Yong-miao. Time-varying information spillover tests and its application to financial markets[J]. Journal of Management Sciences in China, 2012, 04:31-39+57.

[6] Wang Jia-hui. The study on international pricing power of copper in Shanghai Futures Exchange[J]. Shanghai Finance, 2008, 06:4851.

[7] Song Jun, Li Peng. An Empirical Study on cross-market arbitrage of international copper markets[J]. China Financial Review, 2007, 1(4): 25-41.

[8] Garbade K D, Silber W L. Price movements and price discovery in futures and cash markets[J]. Review of Economics and Statistics, 1983, 65(2): 289-297

[9] Hamao Y, Masulis R W, Ng V. Correlations in price changes and volatility across international stock markets[J]. Review of Financial Studies, 1990, 3(2): 281-307.

[10] Sadorsky P. Time-varying risk premiums in petroleum futures prices[J]. Energy economics, 2002, 24(6):539-556.

[11] Korkie B, Sivakumar R, Turtle H J. Variance Spillover and Skewness in Financial Asset Returns[J]. Financial review, 2006, 41(1):139-156.

[12] Hashmi A R, Tay A S. Global regional sources of risk in equity markets: evidence from factor models with time-varying conditional skewness[J]. Journal of International Money and Finance, 2007, 26(3):430-453.
[13] Hong Y M. Testing for Independence Between Two Covariance Stationary Time Series[J]. Biometrika, 1996, 83(3):615-625.

[14] Hong Y M. A Test for Volatility Spillover with Applications to Exchange Rates[J]. Journal of Econometrics, 2001, 103(1-2): 183224

[15] Hong Y M, Chen S W, Liu Y H, Wang S Y. Extreme Risk Spillover between Chinese Stock Market and International Stock Markets[J]. China Economic Quarterly, 2004, 3(3):705-728.

[16] Hong Y M, Liu Y H, Wang S Y. Granger causality in risk and detection of extreme risk spillover between financial markets[J]. Journal of Econometrics, 2009, 150(2):271-28.

[17] Zhao Liu-yan, Wang Yi-ning. Information Flows and Volatility Spillover across A Share and B Share Markets of China[J]. Journal of Financial Research, 2003,10:37-52.

[18] Dong Xiu-liang, Cao Feng-qi. Volatility Spillover Effects and Risk Contagious: Evidence from the Domestic and Foreign Stock Markets Based on the MGARCH Mode[J]. Application of Statistics and Management, 2009(6):1091-1099.

[19] Chen Yun, Chen Lang-nan, Lin Wei-bin. Estimating RMB internal equilibrium real exchange rate and misaligment from 1997 to 2007. Statistical Research, 2009(6):1091-1099.

[20] Shen Pei-long, Xing Tong-zheng. GARCH Model Based WTI and Brent Crude Oil Price Risk Analysis[J]. Journal of Harbin Institute of Technology, 2010(3): 88-93.

[21] Cai Jian, Guo Ju-e, Gong Li, Wang Shou-yang. Estimating crude oil price 'Value at Risk' using the Bayesian-SV-SGT approach[J]. Systems Engineering-theory \& Practice, 2011(1): 8-17.

[22] Liu J H, WANG Y B, Wang J J, Wu X, Zhang S. Is China the price taker in soybean futures? [J]. China Agricultural Ecomomice Review, 7(3):1-17.

[23] Chen Y R. VaR Method and Its Application in Risk Management of China' s Stock Market[M]. Guangzhou, South China University of Technology, 2010.

[24] Tao Wei. Empirical Study and Application of VaR and CVaR Based on GARCH Group Models[J]. Statistics and Decision, 2012,09:77-80.

[25] Engle R F. Autoregressive Conditional Heteroscedasticity with Estimates of the Variance of United Kingdom Inflation[J]. The Econometric Society, 1982, 50(4): 987-1007.

[26] Nelson D B. Conditional Heteroscedasticity in Asset Returns: A New Approach [J]. Econometrica, 1991, 59(2): 347-370.

[27] Granger C W Investigating Causal Relations by Econometric Models and Cross-spectral Methods[J]. Econometrica, 1969, 37(3): 424-438.

[28] Sims C A. Money, Income, and Causality [J]. The American Economic Review, 1972, 62(4):540-552. 